\title{
Performing School Failure: Using Verbatim Theatre to Explore School Grading Policies
}

\author{
Rebecca M. Sánchez
}

\begin{abstract}
This article describes how dramatic writing and performance practices can be used to reshape qualitative interview data into a verbatim theatre performance with the intent of drawing attention to social movements in education. The performance described in the article reveals the consequences of a punitive educational policy agenda and addresses the emotional toll school grading and other neoliberal policies have had on teachers at a school in the southwestern United States. A primary objective is to examine and explore how verbatim dramatic writing and performance tactics can amplify current issues and social dilemmas and evoke an emotional response in the absence of dramatic action. The methods of writing a script from qualitative data are presented for other scholars and educators who intend to create performances from data.
\end{abstract}

\section{Performing School Failure: Using Verbatim Theatre to Explore School Grading Policies}

"The arts are more than mere entertainment. In my view they should also be the vessel which houses the conscience of a nation; they should ask the difficult questions others would rather leave unasked."

(Soans, 2008, p. 17).

The living room was no longer a living room. It was a theatre with a live audience. Teachers, preservice educators, university professors, community members, artists, and several children crowded into the space to see a performance called This Scarlet $F^{l}$ about school grading initiatives in the United States. In recent years, some states in the United States have used student achievement data to assign letter grades (A to F) to public schools (Crawford-Garrett, Sánchez, \& Tyson, 2017; Murray \& Howe, 2017). In the southwestern state where the performance took place, many schools were assigned $\mathrm{D}$ and $\mathrm{F}$ grades by the state Public Education Department (PED).

After some mingling and catching up, the performance was announced and the audience members found seats. Although data was not collected from the audience about their impressions of the play, their responses to the live performance in real time were noted. The lights darkened and the sounds of a popular educational protest song played. In the dark room a transition occurred, both literally and figuratively. Literally, the performance began and the sounds of the audio postcards could be heard through the speaker. Figuratively, the mood of the group was altered into that of audience. Audio postcards played and the audience listened to three children and one mother sharing stories about their favorite teachers. In the darkness, the audience of about 40 people nodded. Hearing the qualities of good 
teachers resonated with the group: support the creation of hands-on activities, maintain an ethic of care, and instill high expectations. As the audio postcards concluded, the lights came up, and an actor, playing the part of a teacher, asked each audience member to retrieve a poem placed under their chairs. Two other actors, from their places in the audience, began reading lines from a poem about school grading policies in the United States. Audience members too, participated in the recitation. Their parts were highlighted and the seamless oral reading of the poem created a stillness in the group. The pain and anguish expressed in the poem became a collective experience and for a moment, audience members became not only actors, but also the characters (the real teachers) they were representing through the oral expression of the text.

Our letter grade you said?

\section{ACTOR 1-AMELIA}

how do you reconcile the letter grade with, with how you feel about the school?

$$
\text { ACTOR 2-MANUEL }
$$

I don't/

$$
\text { ACTOR 3-HEATHER }
$$

I don't care about the grade/

ACTOR 1-AMELIA

I could care less about the letter grade. It means nothing to me.

...we don't care about, that.

ACTOR 2-MANUEL

but the problem is

it has affected our enrollment

but I don't think any of us pay attention to that.

But the kids all knew we were an $\mathrm{F}$ school.

We're an F, F, F, F, F.

they had already deemed themselves $F$,

\section{AUDIENCE MEMBER 1}

but all the $\mathrm{F}$ means is that we're one hundred percent free and reduced lunch.

I just let it go,

it's a practice in letting go. . .

those worrisome, weird labels can bring you down if you're not careful.

I really don't think it's an F, I know kids say that, but it's not,

"you're an F,

at an F school",

I'll be the danged Best $F$ you've ever seen.

You wanna see F? I'm kind of defiant like that.

But I just think about, the $F$ grade

\section{AUDIENCE 2}

but I think about the students that are here, so many gifts, they have so many languages, they have so many talents, how can you reconcile the kids with the grade? and I think if you give enough negative self-talk you create self-fulfilling prophecy I'm a master teacher, being dragged down to the ranks of a novice that is so demoralizing. It is so demoralizing And offensive, it's just plain offensive. (Poem continues) 
As the poem concluded, the three actors made their way to the front of the room toward the "stage" and took their places on stools. Each presented a monologue about school grading containing moments of humor, despair, and hope. The monologues were interspersed with brief exchanges of dialogue, highlighting and punctuating the way a person tells a story. For example, in Amelia's monologue the following exchange takes place:

AMELIA

I am fully, fully aware that $90 \%$ of our, school grade is based on standardized test scores, a standardized test score. Our school grade, teacher evaluation, is hinging on an unproven test. Can you imagine going to an elementary school and knowing that your school has a grade of an F? And, and you're told all the time, you know, MANUEL

if you get an $\mathrm{F}$, you're failing.

AMELIA

Can you imagine? All of our students go to a school that has a grade of an F, HEATHER

Their parents willingly take them to a school with a grade of an $\mathrm{F}$. MANUEL

An $\mathrm{F}$,

AMELIA

An F, and that's around, the idea of an F, so of course the impact is awful. There're schools that get an F grade year, after year, after year, after year. And when you get an F you don't get all the support. When teachers subconsciously know that as long as we're given a grade based on that test score we will always be an F grade, that is demoralizing. It's demoralizing for parents, it's demoralizing for children, it's not a motivator, to do better. It is demoralizing. And it is demoralizing because the, the implied message from the PED, and from the mainstream media, is we are an F because,

There're bad teachers at our school, MANUEL

and there's a lot of people, who imply there're bad parents, too.

As each actor performed a monologue, the complex emotions teachers feel for children were expressed and contextualized within the current policy environment that quantifies and grades children, their teachers, their schools, and their communities (Murray \& Howe, 2017). The performance concluded with music playing in the darkness and the audience was given a moment to sit with the ideas presented.

The views of the teachers presented in the scripted performance are not commonly heard in public spaces. Rather, in the United States a different script, a manufactured script, dominates public discourse in education. Headlines such as, "Why we must fire bad teachers" permeate mainstream media (Thomas, 2010). Reichel (2018) argues, "the entertainment and news media have both tended to portray teachers as a central part of the problem, treating them variously as inept, lazy, out-of-touch..." (p. 483). Policy reactions have tended to favor the use of standardized controls and high-stakes testing to rate students, schools, and teachers (Giroux, 2016; Lipman, 2011). 
In performing a script developed using the words of the teachers, an alternative narrative was disseminated to the public. Educational researchers committed to social justice and equity, must heed the call to disseminate research findings in compelling and alternative ways (Kelly, 2019). Performance is one way to expand the audience for educational research. This evening of verbatim theatre was the culmination of a scriptwriting practice and performance inquiry. The aim of the inquiry discussed in this article is to describe how dramatic writing and performance practices can be used to reshape qualitative interview data into a performance with the intent of drawing attention to social movements in education. As such, a primary objective is to examine and explore how dramatic writing and performance tactics can amplify current issues and social dilemmas and evoke an emotional response in the absence of a plot based on dramatic action. The aims and objectives are rooted in a long commitment as an artist and educator to principles of democracy, social justice, and emancipatory practice.

\section{Background}

In 2013, I began working with two colleagues and a group of public school teacher activists attempting to reveal the unintended consequences and negative impacts of an aggressive and punitive neoliberal accountability structure. Neoliberal policies in education have resulted in increased standardization, overuse and misuse of standardized tests, and privatization efforts (Au \& Ferrare, 2015). In this case, teachers, traumatized by the working conditions and unreasonable high-stakes testing expectations, have slowly organized to educate the public about the policies (Crawford-Garrett et al., 2017). The imposed accountability structure, saturated with a neoliberal agenda, has had a chilling effect on creative instruction, and has also resulted in the emnification of teachers, communities, and children (Giroux, 2016).

As part of the accountability structure, schools in the U.S. state where these teachers work were assigned grades by the Public Education Department (PED) and a majority of schools were deemed as D or F schools. A 2018 study indicates that 16 U.S. states have initiated school grading policies (Murray \& Howe, 2017). The same report indicates:

...there is good reason to think that many such A-F report card systems are technically flawed: they fail to validly measure and represent school quality, and they typically fail to drive the school improvement they promise. There is also good reason to think that they are democratically flawed: they typically fail to measure, and reward or punish, how well schools promote good democratic citizenship (p. 3).

However, in spite of the flaws inherent in the school grading system, school grading policies were developed under the guise of promoting transparency related to school quality (Murray \& Howe, 2017), and many parents and community members rely only on common understandings associated with A-F.

As activist scholars, artists, and educators, my two colleagues and I attended school board meetings, community meetings, and engaged in protests along with the teacher participants from the initial study. In conducting the research study, one of our initial goals was to understand the experiences of the teachers working at the school. Additionally, we wanted to broadly disseminate the findings to audiences 
within academia, but also to a teacher-practitioner audience and our community. While the mainstream media has reported on the activism, the tone often implies the teachers are cranky and afraid of accountability and the news reporting questions their competence. The old adage "if you are doing your job, why are you afraid," characterizes the mainstream journalism on the topic. The script in this article is based on a qualitative study on school grading. The participants in the study were 13 teachers at a public elementary school in a southwestern state in the United States. Data collection consisted of interviews with individual teachers at a school designated an F by the PED. A focus group was conducted to substantiate the initial findings and to follow up with additional questions. Data was coded for themes. A study of the findings related to trauma was published by the research team (Crawford-Garrett et al., 2017). An additional article collectively written by the teachers and the researchers was published in a teacher magazine to highlight the activism.

\section{Role of the Researcher}

I have spent my career as a teacher educator at a public research university in a southwestern state in the United States. My teaching and research have centered on investigating ways to support teachers throughout the professional lifespan. Moreover, I am interested in how contemporary and historical narratives shape teacher understandings of social phenomena. I attempt to prepare teachers to critically question how official narratives operate as fact.

Recently, I began exploring how arts can be used to prepare teachers to address the needs of diverse children. In working with the arts in teacher education, I became curious about developing my artistic impulses through formal study. I enrolled in a Master of Fine Arts program in dramatic writing at the university where I teach. Initially, my thought was that through study I would be able to support teachers and children in writing creative theatrical dramas. As I studied playwriting, I became more committed to my own development as an artist.

Upon completion of the study, I revisited the data using an artistic analytic process. The performance on school grading emerged because I became increasingly interested in finding a way to communicate the experiences of the teachers to the local community. Furthermore, as a playwriting student I was beginning to see theatre potential in research data. One of our regular exercises in the playwriting courses was to take overheard dialogue and construct it into short plays. This practice came to mind as I looked at the qualitative data from the school grading study. My inspiration to craft a performance from the data was also motivated by my desire to communicate the story of the teachers to our local community. With the support of the teacher participants I crafted the performance.

Data was curated into a performance with three parts: audio postcards curated from the voices of children and a parent, an opening interactive poem, and three monologues. Audio postcards are short recordings of people addressing a particular experience or prompt. They are often place-based, but in the case of this performance they were reflective postcards to great teachers (Sánchez \& Spurlin, 2009). The interactive poem was devised from the exact words extracted from the focus group interview. The remaining three monologues were developed using only text from the individual interviews with 
teachers. The first monologue speaks to teacher activism and resistance to the school grading policy. The second monologue addresses the toll of the grades on teachers. The third monologue describes how the teacher talks to the kids at his school about the grade. As a whole, the performance is a curation of teacher voice describing the impact of the school grading system on teachers, children, and communities.

\section{Practice Lineage}

The inquiry emerges from a robust theatrical and activist practice lineage. Aristotle and the Poetics (1995), historical and contemporary dramatic writing traditions, qualitative research methodologies, and performance practices influenced the development of the script and performance. However, theatre for social justice and verbatim theatre point more directly to the practices engaged in this inquiry.

\section{Theatre for Social Justice and Change}

Theatre for social justice and change, like that created by Teatro Campesino, has been influential to my understanding of activist theatre. Teatro Campesino uses pedagogies and stories of the field to create theatre specifically geared to farmworkers and migrant workers (Broyles-González, 1994). This theatre offers both the performers and the audience an opportunity to examine their reality with the intent of empowering marginalized communities. In the act of viewing, and reviewing power dynamics and markers of oppression, the audience acquires a new vocabulary to name their world. Much like the literacy circles of Freire (1970), and the Theatre of the Oppressed (Boal, 1985), Teatro Campesino activates audiences and performers to take critical steps toward their own liberation. The plays themselves are both nonfiction and fiction, allegorical and realistic, but in their own ways re-created the familiar lives of the often oppressed farmworkers (Broyles-González, 1994).

\section{Verbatim Theatre}

Verbatim theatre extends from the Social Justice theatre tradition and is also related to Documentary Theatre (Derbyshire \& Hodson, 2008; Taylor, 2013). However, rather than merely presenting nonfiction, representative, or allegorical theatrical representations of reality, the script emerges in a word-for-word account of the participant-articulated experience (Derbyshire \& Hodson, 2008). As such, it becomes a living piece of data for audiences to interpret and analyze through performance. Furthermore, Soans (2008) identifies that the "audience for a verbatim play will expect the play to be political" (p. 19). Playwrights can call attention to social causes and use verbatim theatre to invite audiences to examine critical issues and pressing social phenomena with an honest telling of experience (Soans, 2008).

Verbatim theatre presents scriptwriters and theatre makers with distinct challenges associated with representation, reactivation of trauma, and decision-making (Derbyshire \& Hodson, 2008). However, as a practice it allows a new way to see and represent experiences. Furthermore, and possibly more importantly, verbatim theatre is a way for theatre to help individuals and groups make sense of the world (Hammond \& Steward, 2008). By involving and incorporating the words of someone directly involved 
in an experience or phenomena into a theatrical work, a democratizing ripple reverberates from the theatre outward (Soans, 2008).

\section{Practice-Based Methodology}

Practice-led research differs from traditional quantitative and qualitative inquiry in a number of significant ways. In his article, "A Manifesto for Performative Research," Brad Haseman (2006) describes some of the key distinctions of practice-led research. The first is a commitment to practice. Rather than beginning with questions, the practice instigates research and nurtures the curiosity. A second feature is the mode of evidence. In practice-led research, the evidential outcome is a work or art, a script, a novel, a sculpture, a dance, a live performance, or other piece of art. Again, the desire in research to use numbers, a quantitative form of evidence, and a qualitative form of evidence, is subverted (Haseman, 2006). The new knowledge emerging from practice-led inquiry requires a direct experience with the art itself. Haseman describes this as "direct (co-presence) or indirect (asynchronous, recorded)" engagement with the art (p. 100). Because this inquiry entailed both the practice of dramatic writing and the production of a theatrical performance-in addition to the examination/utilization of an existing qualitative data setnumerous insights were gained related to verbatim scriptwriting and performance.

This inquiry is grounded in the practices of dramatic writing and theatrical performance. As such, a number of practices contribute to the study. At the root of the scripted performance is the script. Because the inquiry is not about devised work, the script itself, and the practices associated with creating the script, are of central importance. However, as this inquiry is investigating the "realness" and compelling nature of a contemporary topic, the performance becomes central. As an artist practitioner, both the scriptwriting and the performance tactics and practices are in dialogue with each other throughout the process. The following sections outline how the qualitative data transformed into a script for performance production.

\section{Theatrical Practices}

The inquiry began with generative practices for theatrical scriptwriting. In creating the script from the qualitative data, I carefully sifted through all of the school grading interviews and the focus group. I created a list of ideas that might inform the script and performance. In this phase I completed a thorough read-through of all study data. I assigned a theme to each interview. I then selected three different interviews based on diverging themes from which to craft the monologues. The themes of the three selected interviews were: activism, trauma, and love of teaching. This choice was based on the desire to create a more comprehensive and compelling performance. Several of the interviews read with similar themes and I wanted each monologue to present a distinct voice on the common issue of school grading. I also continued to look for theoretical and practical resources related to performing qualitative research. 


\section{Curating Postcards}

The opening moments of the performance present a set of four audio postcards recorded by my daughter, two nieces, and sister. They each describe memorable teachers and the qualities that make the teachers outstanding professionals. The postcards are the result of an impulse to make/curate a small piece of art outside the realm of the formal research study. The personal postcards from my family at the beginning of the performance contextualize me as an artist because through the postcards I can also identify and present my own value judgments, priorities and I can publicly own my position because I share the views of quality teaching presented in the postcards and I intentionally selected the people to share stories. Finally, the postcards are a way to preserve art creation and movement politics as something beyond institutional control associated with research. The inclusion of the audio postcards is a small gesture resisting neoliberal ideologies based on control and managed inquiry.

\section{Script Writing}

Monologues were a natural choice because the data is largely in the form of individual interviews. In the process of crafting each interview, I first removed all interviewer and participant labels from the exchanged dialogue. I then "cleaned" each interview up. The cleaning phase entailed fixing contractions, typos, and removing many of the disconnected sentence fragments present in the transcript. For example, in Heather's interview, she had this to say about professional practice associated with school grading:

Heather: So, I'm, I'm very disturbed that my leaders are modeling, that they would come to us as [?] and say we're an F school. So I want to say to people, I want to say, do you want me to go into the classroom and do that with kids? You are F children, it's, it's, we know that this is not a good, um practice for making growth and for encouraging self-esteem or learning.

Interviewer: Right.

Heather: And so if they think up above that that putting this scarlet $F$

Interviewer: Umhmm

Heather: on us is going to trickle down to the kids in a positive way, they're so wrong. I think that's the strongest thing, the thing about it, it's like they should be modeling, it's like, um, education 101, you find the strengths in your child and you nurture them. You don't focus on the one wrong thing they're doing and like slap them around, it's like they're doing the worst educational practice on, on, on, on a school setting that you could possibly do. I do believe that things trickle down like that.

The interview exchange was included in a monologue and the raw data in the previous segment became this:

\section{HEATHER}

I want to say to people, do you want me to go into the classroom and do that with kids? You are F children? We know that this is not a good practice for growth and for encouraging self-esteem and learning. If they think up above that putting this scarlet $F$ on us is going to trickle down to the kids in a positive way, they're so wrong. 
I attempted to maintain the semantic thrust of the raw data, but I also wanted clean the passage up for performance. It should be noted however, that all of the words included in the performance script were taken directly from the interview and presented in the same order. However, some fragments were not removed, especially if they contained theatrical power.

I then selected chunks of the interview that told the thematic story for each participant. Once the interviews were abbreviated, sculpting occurred. This mainly consisted of trimming each monologue into a manageable size and making each utterance count. In each of the three selected interviews, I noticed instances in which the participant re-created conversations about school grading and policies. I decided to maintain some of these exchanges and to punctuate each monologue with the dialogue. This choice was a deliberate attempt to interrupt some of the long monologue sequences for performance effect.

\section{Theatrical Elements}

Another performance practice is related to making choices about light and sound. I chose music from popular culture with themes of educational resistance to use for transitions. I also identified a visual image for the poem and for each monologue. The defining image was selected based on the content of the poem or monologue. For example, when the poem was being read the spotlight slowly began to illuminate the front of the stage. As the audience participated in the poetry reading and listening, the focus was moved from the collective to the individual through the use of the spotlight, in our case, a projector light. Later in the performance, Amelia, one of the characters presenting a monologue repeatedly speaks of acts of protest. As she performed her monologue, a "down with testing symbol" was projected over her body. Heather mentions the way the accountability structure is taking a physical toll on her body, so splatters of blood appear on her (through projection) as she performs her monologue. In his monologue Miguel speaks about the $\mathrm{F}$ grade the school received 41 times. As his monologue is performed, $41 \mathrm{Fs}$ are projected unto his body, one at a time, until he is tattooed with Fs.

\section{Praxis}

The praxis of the school grading performance resides along parallel research planes. It is characterized by the intersection of performance ethnography, performance research, verbatim theatre, and activist traditions. According to O'Neill et al. (2002), "Performance science makes more accessible the contested and multiple versions of reality, and the unheard voices and experiences of individuals who may consider themselves powerless" (p. 71). In the process of writing, theorizing, and performing, an alternative active stance is developed. The resulting knowledge and insights inform both the process of scriptwriting, and the act of performing politics.

\section{Scriptwriting: Creating a Dramatic Response}

During the process of crafting the script, significant insights were gained. When writing a new script from existing text, the first challenge is altering the text and the order as little as possible to maintain integrity. 
This results in the honest and "revelatory and truthful" portrayal of experience (Soans, 2008, p. 19). Upon careful examination of the interview data and text, it became clear that certain words contain linguistic and theatrical power, and though they do not advance or further dramatic action, or a plot, they call attention to specific incidents and create a dramatic response. This points to the interest that can be created in theatre around dramatic response as opposed to the more traditional dramatic action. For example, the phrase "was literally killing me" in the following monologue excerpt is a powerful phrase eliciting a strong emotional response.

\section{HEATHER}

A couple years ago when I was at another school, my work load, because of these policies and what's expected of me, was literally killing me, literally. And at the end of one year, I was like, my body, I'm just gonna die physically. I'm just gonna break in half, I felt like the load was impossible.

The follow-up phrases "die physically" and "break in half" contribute to the overall emotional response of the viewer. When a live person performs phrases such as these in real time, the emotional impact is further amplified and an audience might empathize with the trauma the teachers experience working in this environment (Crawford-Garrett et al., 2017).

Paying attention to the repetition in the text was also a powerful compass in the scriptwriting process. The following excerpt comes from the transcription of the raw data. Amelia, a teacher at the school, talks about the impact of the $F$ grade:

So, it's demoralizing. It's horribly demoralizing. And it's, it's, it's, you know, horribly demoralizing to hear that the reason that we have to have our schools grading, the reasons that we have to be evaluated as teachers is because the children aren't doing well on tests, those tests. Not for any other reason. So. Yeah. It's demoralizing.

In a paragraph with five sentences the word "demoralizing" is used four times. Repetition such as this became instrumental in making writing choices for Amelia's monologue. I knew I had to include some information about the demoralizing aspects of school grades since it was a source of frustration for her. Later, in the interview she revisits the idea of demoralization. The script includes the following exchange:

AMELIA

When teachers subconsciously know that as long as we're given a grade based on that test score we will always be an $\mathrm{F}$ grade, that is demoralizing. It's demoralizing for parents, it's demoralizing for children, it's not a motivator, to do better. It is demoralizing. And it is demoralizing because the, the implied message from the PED, and from the mainstream media, is we are an F because,

\section{HEATHER}

there's bad teachers at our school,

MANUEL

and there's a lot of people, who imply there's bad parents, too. 
Sometimes interview data doesn't follow a traditional storytelling arc. There may not be a plot, or dramatic action in the interview. However, repetition itself is another example of a way to create dramatic response from the audience in the absence of dramatic action. In the case of activist teachers, the repetition becomes almost a parallel example of political movement speech and the repeated words and phrases take on a protest chant structure.

In writing the monologues, I read for exchanges. In doing so, I was able to pepper the monologues with moments of dialogue. This opened the monologue structure up and added aural interest. I was concerned with monotony and discovering the existing dialogue in the interviews was something I chose to capitalize on for theatrical interest and to enhance the dramatic response with the audience.

\section{MANUEL}

No 'cause my test scores, like I said, random. I really don't like when kids' efforts are diminished in so cavalier a way, that no matter how good they did,

HEATHER and AMELIA

You're still an F school!

MANUEL

You're an F school or you know, you went up to a D.

'Cause kids know... what it is, they all have older brothers and cousins and they know Ds suck. HEATHER AND AMELIA

Ds suck.

HEATHER

We're a D.

AMELIA

doesn't that suck?

MANUEL

And I was like, that sucks that somebody graded us that, yeah. Are you a D student?

HEATHER and AMELIA

No!

As the teachers break from monologue to dialogue, there is attention drawn to a collectivity drawing the audience in to that collective.

Using a monologue format resulted in a script that explores the larger issues of school grading with distinct stories and perspectives. The process of writing a verbatim theatre script is powerful as a dramatic 
writing practice, but an unexpected finding is that the act of scriptwriting became a form of data analysis in relation to the qualitative study.

\section{Performance: Humans and the Amplification of Emotional Impact}

Just as the practice of scriptwriting produced powerful findings, the performance itself illustrated new insights. Elevating speech acts extracted from the interviews and compiling them into a script has power. However, when humans perform the script, the emotional impact is amplified. The script coming to life in real time, through the performance of the actors, reminded audience members of the human cost of the school grading initiative. School grading is often defended by public officials with a discourse characterized by use of data, graphics, and information points. Rarely do we get to assign faces and humans to the policy. With a performance, crafted from the words of teachers themselves, the emotional dimension of the policy initiative took the fore as actors embodied the experience of the teachers.

The relationship of the audience to the topic can create unexpected reactions. Noneducator audience members were able to experience moments of humor in the script. Even though there was a serious tone, the life brought to the words by the actors made some moments funny. For example, the poem extracted verbatim from the focus group interview contains the following lines:

\section{AUDIENCE MEMBER}

But [The Governor] is going to fix that.

she's going to give us pre-paid debit cards with

100 dollars

100 dollars for us to. . .

100 bucks.

100 dollars. . .

For supplies

For supplies for the year. . .

In the raw data from the focus group interview, the teachers had a lively discussion about how receiving gift cards from the Governor was a sorry remedy for all of the punitive educational policies that vilify teachers initiated under her administration. However, when this part of the poem was read during the performance, there was laughter from the noneducator audience. In performance, the absurdity of the 100-dollar gift measure was revealed and the laughter pointed to the irony of this educational structure. A teacher audience shook their heads in disgust during this portion of the performance and during a postperformance discussion they reflected on this part of the performance. The 100-dollar gift card was beyond funny for teachers intimately involved with the inadequate gesture. 
A further finding has to do with audience expectations of the performance and the examination of literal and figurative space. Is the audience expecting theatre? Is the audience expecting research? This shapes the entertainment value of the performance. For example, when performed in an academic venue this performance generated perhaps more excitement than when performed for a theatre audience. Regardless of audience expectation and venue, the relationship of the performers and the moments of dialogue automatically add layers of camaraderie, relationship and evoke a community feel to the data. Through the process of embodiment and the brief exchanges, the monologue form was fractured, and actors transcended the performance space to evoke a sense of shared activism. This shared activism is not present in the interviews alone; it is only through the structuring into the monologue form with moments of dialogue that the shared experiences comes to the surface.

\section{Concluding Thoughts}

Performing research has the potential to disseminate significant findings outside of the academy and to advance social movements. In the case of the inquiry presented in this paper, the teacher participants had the opportunity to be heard by the larger community where they live. Furthermore, in performance, the teacher participants, who were already demonstrating an activist stance throughout the course of the study, were able share their vision of love and care for the children they serve. They broke from the manufactured script that refers to children as data points and they reminded themselves, the research team, and the larger public, that the teaching profession is an emotional and loving act of service. Scriptwriting and performance tactics can effectively amplify a message and create an emotional response even in the absence of dramatic action. When the performance concluded, the audience was challenged to revisit simplistic notions of school grading. They were left to consider their own priorities and to ask bigger questions about education. For all involved, the performance of This Scarlet $F$ served as an opportunity to resist dehumanizing policies. The following excerpt was the concluding passage of the performance in which the teacher Manuel moves away from talking about the $\mathrm{F}$ grade and focuses instead on capturing the complexity that educational standardization overlooks, thereby re-centering the audience on the value of relationships that emerge from shared humanity.

\section{MANUEL}

When you sit with a teacher and you see the way they work with kids and you see the love, and you see the genuineness, and you see it all, and you say, "Wow! That is exactly what I want to do." When I see other people doing it, it only makes me feel even more passionate about what I am doing. 'Cause I know I've seen love and that's one of the first things I tell my kids. I love you guys. Thank you for coming to my class 'cause I don't even have a class, I don't even have a job, without you. So if you're not here, neither am I. So thank you for being here and you know, let's make this work. And we are going to be better this year because you are here with me and I'm here with you. And I'm sure we will be better at the end. 


\section{Note}

1. The script of This Scarlet $F$ will be published in its entirety in Emancipating Education: Considerations of Deferred Dreams and Visions for Change. D. Kemp (Ed.). Findings from the qualitative research study have been published in Critical Education. The APA citation for the qualitative study findings is as follows: Crawford-Garrett, K., Sánchez, R., \& Tyson, K. (2017). "If I give one more piece, it's gonna be the end of me." The trauma of teaching under No Child Left Behind. Critical Education, 8(3), 1-21.

\section{References}

Aristotle. (1995). Poetics. Harvard University Press.

Au, W., \& Ferrare, J. J. (2015). Mapping corporate education reform : power and policy networks in the neoliberal state. Routledge.

Boal, A. (1985). Theatre of the oppressed. Theatre Communications Group.

Broyles-González, Y. (1994). El teatro campesino: Theater in the Chicano movement. University of Texas Press.

Crawford-Garrett, K., Sánchez, R., \& Tyson, K. (2017). "If I give one more piece, it's gonna be the end of me." The trauma of teaching under No Child Left Behind. Critical Education, 8(3), 1-21

Derbyshire, H., \& Hodson, L. (2008). Performing injustice: Human rights and verbatim theatre. Law and Humanities, 2(2), 191-212.

Freire, P. (1970/2000). Pedagogy of the oppressed (30th anniversary ed.). Continuum.

Giroux, H. A. (2016). Defending educators in an age of neoliberal tyranny. Tikkun, 31(4), 46-49.

Hammond, W., \& Steward, D. (2008). Verbatim, verbatim: Contemporary documentary theatre. Oberon.

Haseman, B. (2006). A manifesto for performative research. Media International Australia, Incorporating Culture and Policy, (118), 98-106.

Kelly, H. (2019). Toward a moratorium on publishing in the field of educational studies: Where is this train going? Educational Studies, 55(1), 1-11.

Lipman, P. (2011). The new political economy of urban education: Neoliberalism, race, and the right to the city. Routledge.

Murray, K., \& Howe, K. R. (2017). Neglecting democracy in education policy: A-F school report card accountability systems. Education Policy Analysis Archives, 25(109).

O Neill, M., Giddens, S., Breatnach, P., Bagley, C., Bourne, D., \& Judge, T. (2002). Renewed methodologies for social research: Ethno-mimesis as performative praxis. Sociological Review, 50(1), 69-88. 
Reichel, M. (2018). Teachers movements in the circuits of communication: From crisis to contestation. Critical Studies in Media Communication, 35(5), 483-502.

Sánchez, R., \& Spurlin, Q. (2009). Listening to the locals, listening to the land. Encounter: Education for Meaning and Social Justice, 23(3), 27-30.

Soans, R. (2008). Robin Soans. In W. Hammond and D. Steward (Eds.), Verbatim, verbatim (pp. 15-44). Oberon.

Taylor, L. (2013). Voice, body and the transmission of the real in documentary theatre. Contemporary Theatre Review, 23(3), 368-379.

Thomas, E. (2010). Why we must fire bad teachers. Newsweek, 67(8).

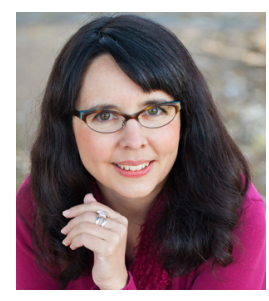

Rebecca M. Sánchez, PhD/MFA, is an Associate Professor specializing in Social Studies Education at the University of New Mexico. She has received numerous National Endowment for the Humanities grants supporting humanities initiatives integrating New Mexico history and culture into the larger narrative of U.S. history. Her research focuses on place-based education, arts-integration, social justice, and social studies education. Her scholarly work has been published in The New Educator, Rethinking Schools, and Critical Education. As a playwright she has received recognition from the Kennedy Center, and she has been an invited observer at the New Play Festival and Workshop at the $\mathrm{O}^{\prime}$ Neill Playwriting Center. 
Rebecca M. Sánchez

218 | LEARNing Landscapes | Spring 2020, Vol. 13 